\title{
Conversion of Isobutane in Presence of Carbon Dioxide over Molybdenum Oxide Catalysts Obtained from Heteropolymolybdate Precursors
}

\author{
Ahmed AOUISSI", Daif ALDHAYAN, Saad ALKAHTANI \\ Chemistry Department, College of Science, King Saud University, Riyadh, Kingdom of Saudi Arabia
}

\begin{abstract}
Molybdenum based oxide catalysts Mo-H, Mo-Fe, Mo-Ce, and Mo-Sn were prepared by calcining $\mathrm{H}_{3} \mathrm{PMo}_{12} \mathrm{O}_{40}, \mathrm{Fe}_{1.5} \mathrm{PMo}_{12} \mathrm{O}_{40}$, $\mathrm{Ce}_{1.5} \mathrm{PMo}_{12} \mathrm{O}_{40}$, and $\mathrm{Sn}_{1.5} \mathrm{PMo}_{12} \mathrm{O}_{40}$ heteropolyanion precursors at $700{ }^{\circ} \mathrm{C}$, respectively. The prepared oxides have been characterized and tested for the dehydrogenation of isobutane (IB) to isobutene in the presence of $\mathrm{CO}_{2}$. The effects of temperature, time on stream, and $\mathrm{CO}_{2} / \mathrm{IB}$ ratio were investigated. It was found that $\alpha$ - and $\beta-\mathrm{MoO}_{3}$ phases were present in all catalysts. Catalytic tests showed that increasing the reaction temperature increased both the conversion and isobutene selectivity, whereas increasing the $\mathrm{CO}_{2} / \mathrm{IB}$ molar ratio increased the conversion but decreased the selectivity for isobutene. Iron was found to be an effective additive element for the enhancement of catalytic activity compared with Ce and $\mathrm{Sn}$.
\end{abstract}

Key words: isobutane; isobutene; heteropoly compound; mixed oxide; carbon dioxide

CLC number: O643 Document code: A

Received 20 March 2012. Accepted 12 May 2012.

*Corresponding author. Tel: +966-1-467-5958; Fax: +966-1-467-5992; E-mail: aouissed@yahoo.fr

English edition available online at Elsevier ScienceDirect (http://www.sciencedirect.com/science/journal/18722067).

Isobutene is one of the most important chemical intermediates with a wide range of applications. It is used as a feedstock in the production of oxygenated compounds such as methyl $t$-butyl ether (MTBE) and alkylates for motor fuels. It is also used widely to produce polyisobutene, butyl rubber, methyl acrylates, and other chemicals. The increasing demand for isobutene has drawn considerable attention towards enhancing its production. Currently, it is produced industrially by the dehydrogenation of isobutane (IB) over a $\mathrm{Cr}_{2} \mathrm{O}_{3}-\mathrm{Al}_{2} \mathrm{O}_{3}$ catalyst at $900 \mathrm{~K}$ [1]. Owing to the endothermic nature of this reaction, elevated temperatures are necessary to achieve acceptable levels of conversion. These extreme operating conditions favor coke formation and catalyst deactivation. As a consequence, the process requires feeds diluted with hydrogen or steam and short reaction cycles with frequent regenerations. Therefore, researchers are pursuing ways to improve isobutene yield and catalyst stability. One route is the oxidative dehydrogenation of IB. In fact, oxidative dehydrogenation is an effective way to increase conversion and lower the reaction temperature. However, as the formation of carbon oxides is thermodynamically more favorable than the formation of isobutene, the selectivity for isobutene decreases rapidly with increase in IB conversion when using oxygen as the oxidant $[2,3]$. Recently, the utilization of carbon dioxide in IB dehydrogenation has been attempted [4-6]. This reaction is attractive because carbon dioxide is affordable and naturally abundant and the resulting process would lead to consump- tion of a greenhouse gas. However, there are still some disadvantages associated with such a process, for example, the isobutene yield and catalyst stability over current available catalysts are still unsatisfactory for practical applications. An improved process would require the development of catalysts that perform well under severely deactivating conditions. For that purpose, several oxides have been tested as catalysts and it has been found that the dehydrogenation strongly depends on redox [7-9] and the acid-base properties of the catalyst [10-12]. This research work deals with the dehydrogenation of IB over a series of oxides prepared from Keggin-type heteropolyanions as precursors.

\section{Experimental}

\subsection{Catalyst preparation}

12-Molybdophosphoric acid, $\mathrm{H}_{3} \mathrm{PMo}_{12} \mathrm{O}_{40} \cdot 13 \mathrm{H}_{2} \mathrm{O}$ and its salts $\mathrm{Fe}_{1.5} \mathrm{PMo}_{12} \mathrm{O}_{40} \cdot 13 \mathrm{H}_{2} \mathrm{O}, \quad \mathrm{Ce}_{1.5} \mathrm{PMo}_{12} \mathrm{O}_{40} \cdot 13 \mathrm{H}_{2} \mathrm{O}$ and $\mathrm{Sn}_{1.5} \mathrm{PMo}_{12} \mathrm{O}_{40} \cdot 13 \mathrm{H}_{2} \mathrm{O}$ were prepared according to a method described previously [13]. The oxides were obtained by calcination of the corresponding heteropolyanions, under an air flow of $6 \mathrm{~L} / \mathrm{h}$ and $700{ }^{\circ} \mathrm{C}$ over $2 \mathrm{~h}$. They were denoted $\mathrm{Mo}-\mathrm{H}$, Mo-Fe, Mo-Ce, and Mo-Sn, referring to their counter-cations $\left(\mathrm{Fe}^{3+}, \mathrm{Ce}^{3+}\right.$, and $\left.\mathrm{Sn}^{3+}\right)$. Another catalyst denoted Mo-(Fe-Ce) was prepared by mixing $1 \mathrm{~mol} / \mathrm{L}$ $\mathrm{Fe}_{1.5} \mathrm{PMo}_{12} \mathrm{O}_{40} \cdot 13 \mathrm{H}_{2} \mathrm{O}$ and $\mathrm{Ce}_{1.5} \mathrm{PMo}_{12} \mathrm{O}_{40} \cdot 13 \mathrm{H}_{2} \mathrm{O}$ aqueous solutions in a volume ratio of 9 . 


\subsection{Catalyst characterization}

The powder X-ray diffraction (XRD) patterns were obtained on Siemens D5000 diffractometer with $\mathrm{Cu} K_{\alpha}(\lambda=$ $0.15418 \mathrm{~nm}$ ) radiation. Fourier transform infrared (IR) spectra of the samples were recorded with a Shimadzu FTIR Spectrometer $8400 \mathrm{~S}$ at ambient conditions by grinding the sample with $\mathrm{KBr}$ and pressing it into a pellet.

\subsection{Catalytic measurements}

Catalytic activities and selectivities were measured using a continuous-flow fixed bed reactor under atmospheric pressure. The catalyst $(0.1 \mathrm{~g})$ packed into a stainless reactor was preconditioned under $\mathrm{CO}_{2}$ flow for $2 \mathrm{~h}$ at the reaction temperature. After pretreatment, the reagent mixture $\mathrm{CO}_{2} / \mathrm{IB}$ with desired molar ratio at a flow rate of $50 \mathrm{ml} / \mathrm{min}$ was fed into the reactor. The $\mathrm{CO}_{2}$ and IB gas flows were controlled by mass flow controller. The reaction products were analyzed with a gas phase chromatograph (Agilent 6890N) equipped with flame ionization detector, thermal conductivity detector and capillary column (HP-PLOT Q, length 30 $\mathrm{m}$, inner diameter $0.53 \mathrm{~mm}$ ).

\section{Results and discussion}

\subsection{Infrared characterization}

IR spectra of the Keggin-type heteropolyanion precursors (before calcination) are shown in Fig. 1. The main characteristic features of the Keggin structure are observed for all prepared catalysts. The bands observed at 1080-1060, $990-960,900-870$, and $810-760 \mathrm{~cm}^{-1}$ are assigned to the asymmetric stretching vibrations of the $\gamma_{\text {as }}(\mathrm{P}-\mathrm{Oa}), \gamma_{\text {as }}$ (Mo-Od), $\gamma_{\text {as }}(\mathrm{Mo}-\mathrm{Oc}-\mathrm{Mo})$ and $\gamma_{\text {as }}$ (Mo-Oc- Mo) bonds, respectively $[13,14]$.

\subsection{XRD measurements}

Table 1 presents the $d$-spacings corresponding to the most significant peaks in the patterns of the four calcined heter-

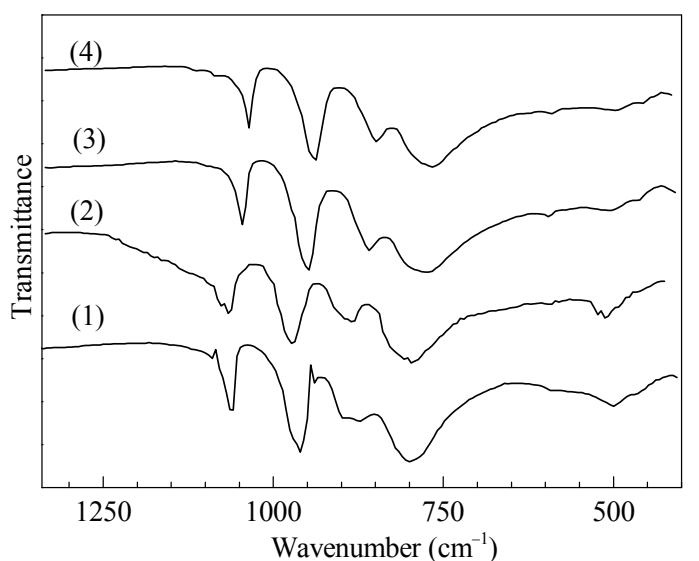

Fig. 1. Infrared spectra of the heteropolyanion precursors. (1) $\mathrm{H}_{3} \mathrm{PMo}_{12} \mathrm{O}_{40} ;$ (2) $\mathrm{Sn}_{1.5} \mathrm{PMo}_{12} \mathrm{O}_{40} ;$ (3) $\mathrm{Fe}_{1.5} \mathrm{PMo}_{12} \mathrm{O}_{40}$; (4) $\mathrm{Ce}_{1.5} \mathrm{PMo}_{12} \mathrm{O}_{40}$.

opolyanions and $\alpha-\mathrm{MoO}_{3}$ and $\beta-\mathrm{MoO}_{3}$. It can be seen that the mixed oxides have slightly different values from the pure oxides. The results indicated that Mo-H presented the typical features related to the most intense lines of the orthorhombic $\alpha-\mathrm{MoO}_{3}$ [15] along with some lines of the monoclinic $\beta-\mathrm{MoO}_{3}[16]$. As for the rest of the catalyst series, it can be seen that besides $\alpha-\mathrm{MoO}_{3}$ and $\beta-\mathrm{MoO}_{3}$, the catalysts contain the iron, cerium and tin oxide resulting from the corresponding cation $(\mathrm{Fe}, \mathrm{Ce}$, and $\mathrm{Sn})$ in the precursor heteropolyanion. The diffraction peaks occurred at $0.3006,0.2702$, and $0.1632 \mathrm{~nm}$ and ascribed to (111), (200), (220) crystal planes are characteristic of the cubic fluorite structured $\mathrm{CeO}_{2}$ (JCPDS 43-1002) [17]. In addition, reflections that are characteristic of $\mathrm{Ce}_{2} \mathrm{Mo}_{4} \mathrm{O}_{15}$ occurred with a $d$ spacing at $0.344,0.325,0.307$, and $0.269 \mathrm{~nm}$ (JCPDS 30-0304). The indexed XRD spectra for the iron oxides showed that the Mo-Fe catalyst corresponds to the orthorhombic ferric molybdate $\left(\mathrm{Fe}-\mathrm{MoO}_{3}\right)$ [18]. As for tin oxide, the observed diffraction patterns at $0.2708,0.2344,0.1505$, and $0.1436 \mathrm{~nm}$ which were associated with the (101), (200), (310), and (301) planes, respectively, are ascribed to $\mathrm{SnO}_{2}$ (JCPDS 88-287) [19]. Nevertheless, other phases could be present as traces. In fact, the coexistence of various phases besides the main phase has been reported for several oxides $[20,21]$.

Table 1 Interplanar spacings of orthorhombic $\alpha-\mathrm{MoO}_{3}$ and monoclinic $\beta-\mathrm{MoO}_{3}$ compared with $\mathrm{XRD}$ patterns of heteropolyanions treated at $700{ }^{\circ} \mathrm{C}$ and proposed assignments

\begin{tabular}{ll}
\hline Precusor & \multicolumn{1}{c}{ Interplanar spacing $(\mathrm{nm})$} \\
\hline$\alpha-\mathrm{MoO}_{3}{ }^{\mathrm{a}}$ & $0.6942,0.3810,0.3462,0.3260,0.2653,0.2308$ \\
$\beta-\mathrm{MoO}_{3}{ }^{\mathrm{b}}$ & $0.3864,0.3559,0.3427,0.3364,0.2687,0.2619,0.2588,0.2562$ \\
$\mathrm{Mo}-\mathrm{H}$ & $0.6789,0.3758,0.3432,0.3228,0.2680,0.2631,0.2509,0.2298$ \\
$\mathrm{Mo}-\mathrm{Fe}$ & $0.7070,0.4585,0.3835,0.3501,0.3280,0.3018,0.2670,0.2555,0.1452,0.1437$ \\
$\mathrm{Mo}-\mathrm{Ce}$ & $0.6901,0.4114,0.3807,0.3464,0.3260,0.3006,0.2881,0.2702,0.2143,0.1988,0.1579,0.1482,0.1449,0.1391$ \\
$\mathrm{Mo}-\mathrm{Sn}$ & $0.6901,0.3810,0.3470,0.3264,0.2708,0.2658,0.2544,0.2344,0.1436,0.1849,0.1601,0.1505,0.1436$ \\
\hline
\end{tabular}

${ }^{\mathrm{a}}$ Ref. [15]; ${ }^{\mathrm{b}}$ Ref. [16]. 


\subsection{Catalytic activity}

\subsubsection{Effect of reaction temperature on IB dehydrogenation}

The effect of reaction temperature was studied in the range $500-600{ }^{\circ} \mathrm{C}$. The dependence of conversion and selectivity on time on stream over Mo-H at different temperatures is shown in Figs. 2 and 3. It can be seen from Fig. 2 that the IB conversion rate remained almost constant with time on stream for the lower reaction temperatures and decreased slightly beyond $4 \mathrm{~h}$ on time on stream for higher reaction temperatures. Similarly the selectivity for isobutene showed the same trend (Fig. 3). As for the variation in conversion and selectivity to isobutene with temperature (Fig. 4 ), the result showed a significant increase at $600{ }^{\circ} \mathrm{C}$. This result is in agreement with that of Skrzyńska et al. [22] where it was reported that the highest temperature below which carbon dioxide was not activated and did not take part in IB dehydrogenation over a $\mathrm{VMgO}_{x}$ catalyst was

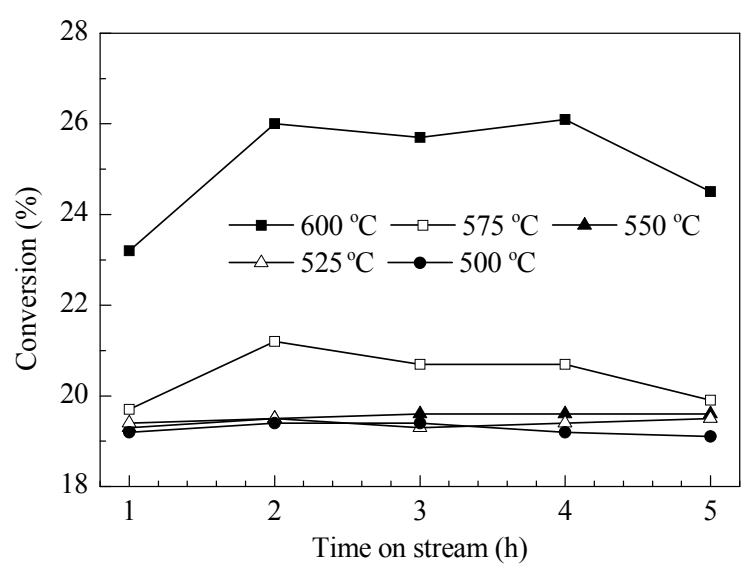

Fig. 2. IB conversion as a function of reaction time at various reaction temperatures. Reaction conditions: $0.1 \mathrm{~g}$ Mo-H catalyst, feed composition $\mathrm{CO}_{2} / \mathrm{IB}=1$ (molar ratio).

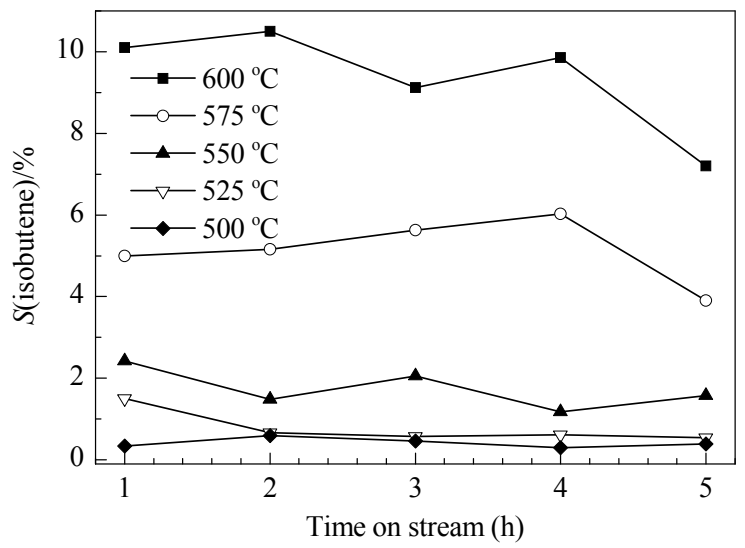

Fig. 3. Selectivity of IB to isobutene as a function of reaction time at various reaction temperatures. Reaction conditions: $0.1 \mathrm{~g}$ Mo-H catalyst, feed composition $\mathrm{CO}_{2} / \mathrm{IB}=1$ (molar ratio).

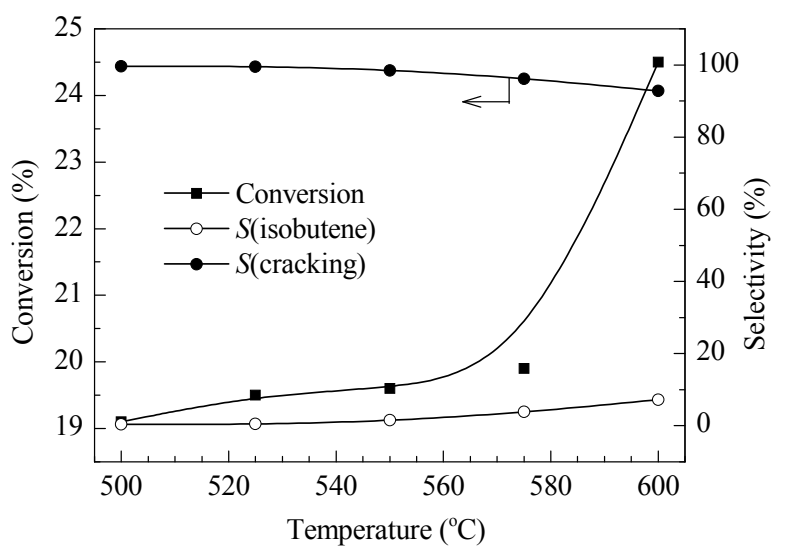

Fig. 4. Conversion of IB and selectivity to isobutene and cracking products as a function of reaction temperature. Reaction conditions: 0.1 g Mo-H catalyst, feed composition: $\mathrm{CO}_{2} / \mathrm{IB}=1$ (molar ratio).

around $527-553{ }^{\circ} \mathrm{C}$. The presence of $\mathrm{CO}_{2}$ enhanced the IB dehydrogenation yield significantly and is generally attributed to the fact that $\mathrm{CO}_{2}$ as a weak oxidant can eliminate hydrogen produced during dehydrogenation through the reverse water gas shift (RWGS) reaction [23-25]:

$$
\begin{gathered}
\mathrm{C}_{4} \mathrm{H}_{10} \rightarrow \mathrm{C}_{4} \mathrm{H}_{8}+\mathrm{H}_{2} \\
\mathrm{CO}_{2}+\mathrm{H}_{2} \rightarrow \mathrm{CO}+\mathrm{H}_{2} \mathrm{O}
\end{gathered}
$$

\subsubsection{Effect of $\mathrm{CO}_{2} / \mathrm{IB}$ molar ratio on IB dehydrogenation}

The effect of the variation in amount of $\mathrm{CO}_{2}$ on IB dehydrogenation was investigated at $600{ }^{\circ} \mathrm{C}$. The $\mathrm{CO}_{2} / \mathrm{IB}$ molar ratio was varied from 1 to 5 . As shown in Fig. 5, the conversion decreased with time on stream for the highest molar ratio and remained almost constant for the lower molar ratios. As for the dependence of conversion and isobutene selectivity on $\mathrm{CO}_{2} / \mathrm{IB}$ molar ratio (Fig. 6), the results showed that the conversion increased with increase in amount of $\mathrm{CO}_{2}$, whereas the isobutene selectivity decreased.

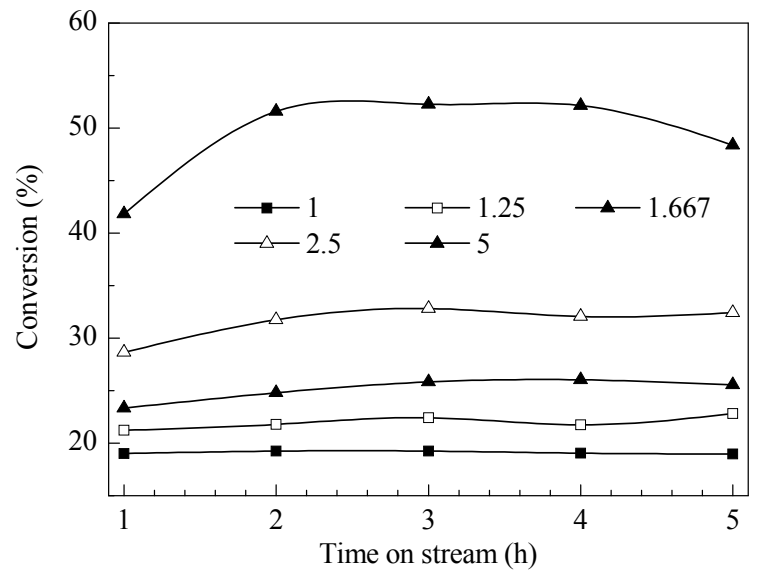

Fig. 5. Conversion of $\mathrm{IB}$ as a function of reaction time at various $\mathrm{CO}_{2} / \mathrm{IB}$ molar ratios. Reaction conditions: $0.1 \mathrm{~g} \mathrm{Mo}-\mathrm{H}, 600^{\circ} \mathrm{C}$. 


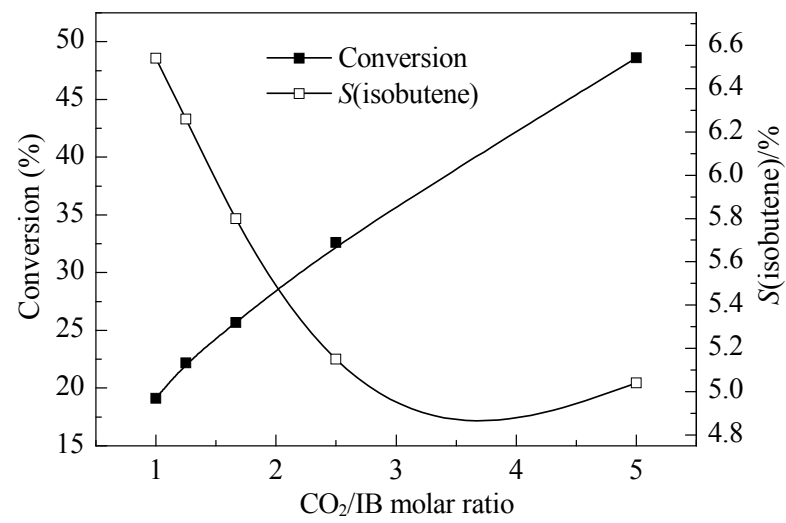

Fig. 6. Conversion of IB and selectivity to isobutene as a function of $\mathrm{CO}_{2} / \mathrm{IB}$ molar ratio. Reaction conditions: $0.1 \mathrm{~g} \mathrm{Mo}-\mathrm{H}, 600^{\circ} \mathrm{C}$.

The decrease in conversion with time on stream for the highest molar ratio results from the increase and accumulation of coke deposition during the reaction. It has been reported $[26,27]$ that the amount of coke deposited on the catalyst increased with increase in reaction temperature and for the $\mathrm{CO}_{2} /$ ethylbenzene ratio, the larger the amount of IB converted, the more coke deposited. This result confirmed that carbon dioxide takes part in the dehydrogenation process, enhancing IB conversion. The carbon dioxide stream was able to gasify a portion of the coke deposit formed on the Mo-H catalyst surface, but did not remove all of the deposit. The rate of coking was faster than that of decoking.

\subsubsection{Reactivity of different oxides}

The activity of four catalysts Mo-H, Mo-Fe, Mo-Sn, and Mo-Ce was compared for the conversion of IB at $600{ }^{\circ} \mathrm{C}$, with a reactant mixture $n\left(\mathrm{CO}_{2}\right) / n(\mathrm{IB})=5$. The results, reported in Fig. 7, showed that IB conversion decreased with time on stream for higher conversion while no significant

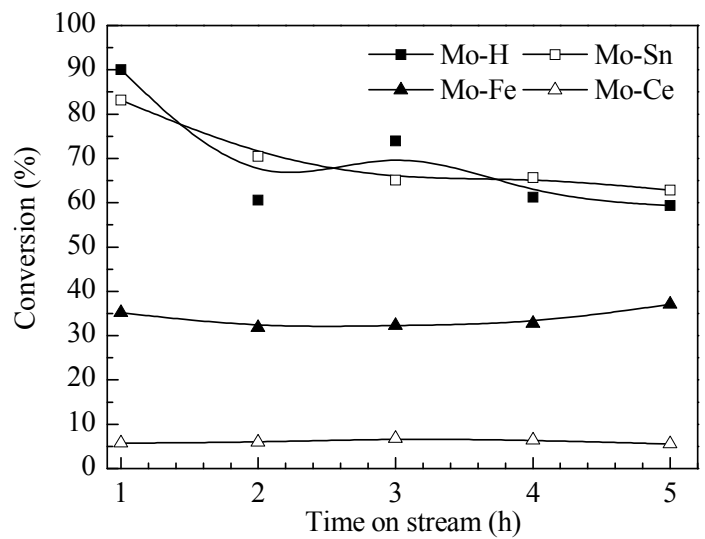

Fig. 7. Effect of time on stream on IB conversion in the presence of $\mathrm{CO}_{2}$ over the series of oxide catalysts. Reaction conditions: $0.1 \mathrm{~g}$ Mo- $\mathrm{H}, 600^{\circ} \mathrm{C}$, feed composition $\mathrm{CO}_{2} / \mathrm{IB}=5$ (molar ratio).

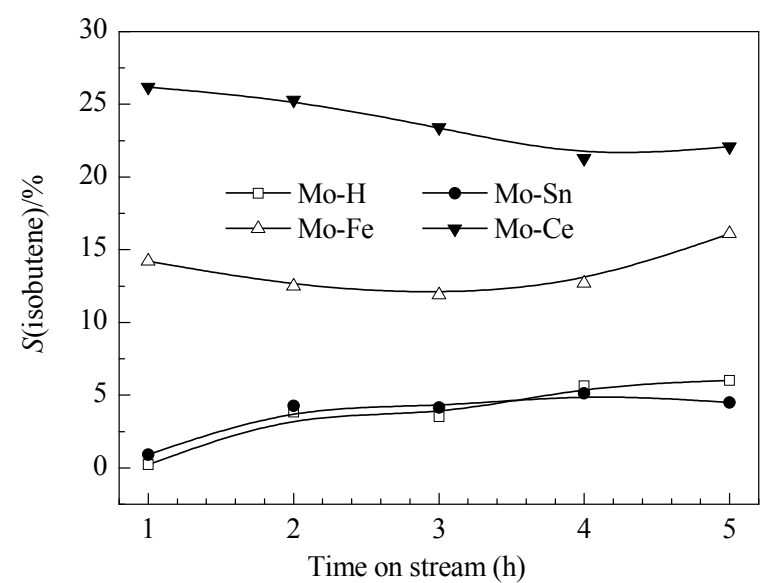

Fig. 8. Effect of time on stream on IB selectivity of isobutene over the series of oxide catalysts. Reaction conditions: $0.1 \mathrm{~g} \mathrm{Mo}-\mathrm{H}, 600{ }^{\circ} \mathrm{C}$, feed composition $\mathrm{CO}_{2} / \mathrm{IB}=5$ (molar ratio).

decrease was noticed for lower conversions. In fact, the conversion obtained over Mo-H decreased from $90.0 \%$ to $59.4 \%$ when the time on stream increased from 1 to $5 \mathrm{~h}$ which represent a decrease of $30.6 \%$. Similarly, the conversion obtained over Mo-Sn decreased from $83.2 \%$ to $62.8 \%$ when the time on stream increased from 1 to $5 \mathrm{~h}$ which represented a decrease of $20.4 \%$. Isobutene selectivity over Mo-Ce decreased with time on stream. The decrease in both the conversion and isobutene selectivity with time on stream suggests that besides catalytic cracking, thermocracking has also occurred.

The conversion and selectivity of the products obtained at $5 \mathrm{~h}$ of time on stream over the series of catalysts are represented in Fig. 9. The results show that the conversion obtained over Mo-Fe and Mo-Ce was $37.1 \%$ and $5.56 \%$, respectively. As for the selectivity, Mo-Fe and Mo-Ce were the most selective to yield isobutene with values of 16.1 and $22.1 \%$, respectively.

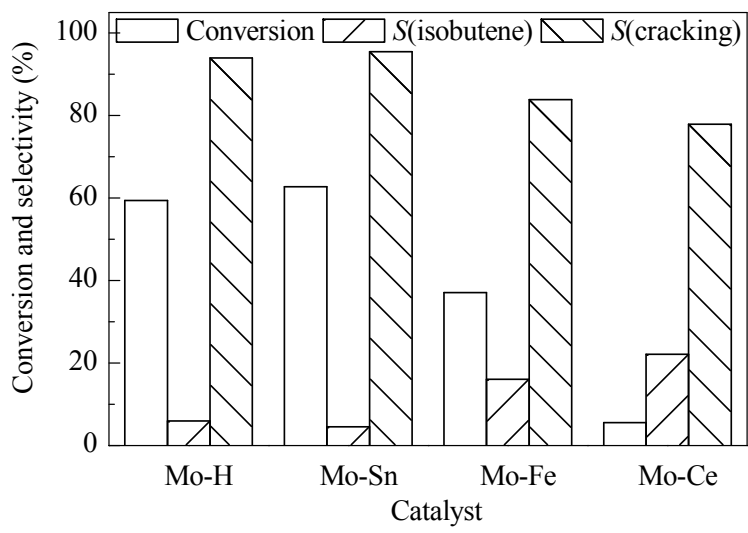

Fig. 9. IB conversion and product selectivities obtained after $5 \mathrm{~h}$ of time on stream over the series of oxide catalysts. Reaction conditions: $0.1 \mathrm{~g}$ catalyst, $600{ }^{\circ} \mathrm{C}$, feed composition $\mathrm{CO}_{2} / \mathrm{IB}=5$ (molar ratio). 


\subsubsection{Reactivity of $\mathrm{Fe}_{2} \mathrm{O}_{3} / \mathrm{Ce}_{2} \mathrm{O}_{3} / \mathrm{MoO}_{3}$ mixed oxide catalysts}

Taking into account that the highest conversion and selectivity of isobutene was obtained over Mo-Fe and Mo-Ce respectively, we attempted to compare the activity of these catalysts with that of the catalyst constituted from both the $\mathrm{Mo}-\mathrm{Fe}$ and Mo-Ce oxides. The catalyst with Mo-Fe/Mo-Ce $=9$ mass ratio designated $\mathrm{Mo}-(\mathrm{Fe}-\mathrm{Ce})$ was tested under the same conditions. The variation in conversion with time on stream is represented in Fig. 10. It can be seen that the Mo-(Fe-Ce) catalyst led to a higher conversion than the $\mathrm{Mo}-\mathrm{Fe}$ and Mo-Ce. Unlike the conversion, the selectivity for isobutene was less than that obtained over Mo-Fe and Mo-Ce (Fig. 11). The highest activity obtained with $\mathrm{Mo}-(\mathrm{Fe}-\mathrm{Ce})$ indicated that Mo-Fe and Mo-Ce have a synergistic effect on IB conversion. It has been mentioned that

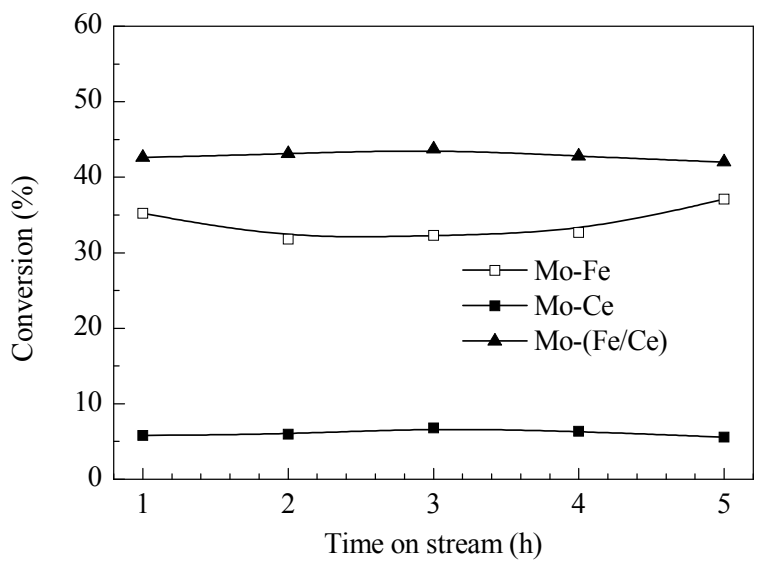

Fig. 10. Effect of time on stream on IB conversion in the presence of carbon dioxide over Mo-Fe, Mo-Ce and Mo-(Fe-Ce) oxide catalysts. Reaction conditions: $0.1 \mathrm{~g}$ catalyst, $600{ }^{\circ} \mathrm{C}$, feed composition $\mathrm{CO}_{2} / \mathrm{IB}$ $=5$ (molar ratio).

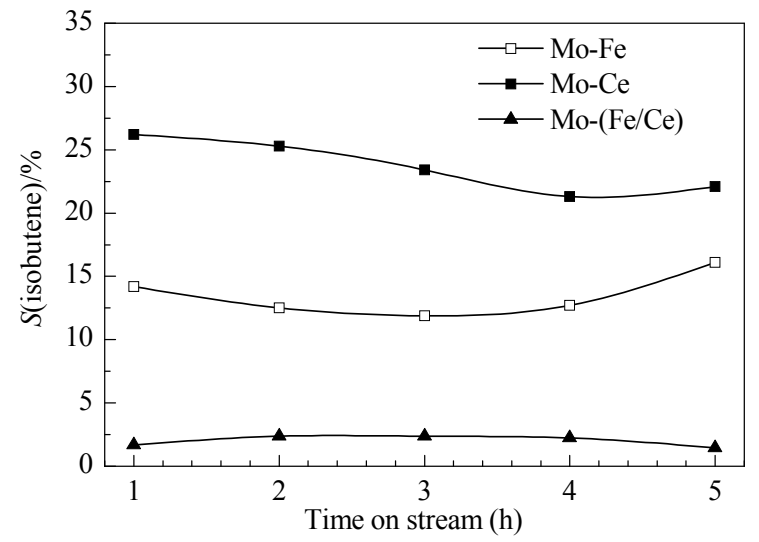

Fig. 11. Effect of time on stream on IB selectivity for conversion to isobutene in the presence of carbon dioxide over Mo-Fe, Mo-Ce and Mo-(Fe-Ce) oxide catalysts. Reaction conditions: 0.1 g catalyst, 600 ${ }^{\circ} \mathrm{C}$, feed composition $\mathrm{CO}_{2} / \mathrm{IB}=5$ (molar ratio). partially reduced ceria can donate electrons to iron oxide in the RGWS reaction [28]. Thus, the presence of $\mathrm{CO}_{2}$ produces redox couples $\left(\mathrm{Fe}^{3+} / \mathrm{Fe}^{2+}\right)$ [25] which can further promote the reduction of ceria and the oxidation of iron.

\section{Conclusions}

Molybdenum-based oxides prepared by calcining Keggin-type heteropolymolybdates as precursors were characterized and tested for their conversion of IB with $\mathrm{CO}_{2}$. The effect of reaction temperature and amount of $\mathrm{CO}_{2}$ was investigated. It was found that all obtained oxides contain orthorhombic $\alpha-\mathrm{MoO}_{3}$ and monoclinic $\beta-\mathrm{MoO}_{3}$ as main phases. Results from the catalytic tests at various temperatures suggested that $\mathrm{CO}_{2}$ is activated and takes part in the dehydrogenation process at $600{ }^{\circ} \mathrm{C}$. The increase in $\mathrm{CO}_{2} / \mathrm{IB}$ molar ratio initially increased conversion but this subsequently decreased with time on stream. The decrease may result from an accumulation of coke deposition during the reaction suggested that the rate of coking was faster than the rate of decoking. Mo-(Fe-Ce) mixed oxides exhibited a higher conversion than that obtained on single Mo-Fe and Mo-Ce oxides owing to a synergistic effect.

\section{Acknowledgments}

The Authors extend their appreciation to the Deanship of Scientific Research at King Saud University for funding the work through the research group project No RGP-VPP-025.

\section{References}

1 Matsuda T, Koike I, Kubo N, Kikuchi E. Appl Catal A, 1993, 96: 3

2 Al-zahrani S M, Elbashir N O, Abasaeed A E, Abdulwahed M. J Mol Catal A, 2004, 218: 179

3 Li L, Yan Z F. Progr Chem, 2005, 17: 651

4 Dias C R, Zavoianu R, Portela M F. Catal Commun, 2002, 3: 85

5 Bi Y L, Zhen K J, Valenzuela R X, Jia M J, Corberán V C. Catal Today, 2000, 61: 369

6 Ogonowski J, Skrzńska E. Catal Lett, 2006, 111: 79

7 Sun A, Qin Z, Chen S, Wang J. J Mol Catal A, 2004, 210: 189

8 Krylov O V, Mamedov A K, Mirzabekov S R. Catal Today, 1995, 24: 371

9 Sun A, Qin Z, Wang J. Appl Catal A, 2002, 234: 179

10 Cai Y, Chou L, Li S, Zhang B, Zhao J. Catal Lett, 2003, 86: 191

11 Wang Y, Ohtsuka Y. Appl Catal A, 2001, 219: 183

12 Xu B, Zeng B, Hua W, Yue Y, Gao Z. J Catal, 2006, 239: 470

13 Aouissi A, Apblett A W, AL-Othman Z A, Al-Amro A. Transition Met Chem, 2010, 35: 927

14 Rocchiccioli-Deltcheff C, Fournier M. J Chem Soc, Faraday 
Trans, 1991, 87: 3913

15 Andersson G, Magnéli A. Acta Chem Scand, 1950, 4: 793

16 Mc Carron III E M. J Chem Soc, Chem Commun, 1986: 336

17 Huang S, Liu S, Zhu Q, Zhu X, Xin W, Liu H, Feng Z, Li C, Xie S, Wang Q, Xu L. Appl Catal A, 2007, 323: 94

18 Massarotti V, Flor G, Marini A. J Appl Cryst, 1981, 14: 64

19 Carriazo J G, Molina R, Moreno S. Appl Catal A, 2008, 334: 168

20 Rashad M M. Mater Sci Eng B, 2006, 127: 123

21 Biernacki L, Pokrzywnicki S J. J Therm Anal Calorim, 1999, 55: 227

22 Ogonowski J, Skrzyńska E. Catal Commun, 2009, 11: 132
23 Ding J F, Qin Z F, Li X K, Wang G F, Wang J G. J Mol Catal $A, 2010,315: 221$

24 Shimada H, Akazawa T, Ikenaga N, Suzuki T. Appl Catal A, 1998, 168: 243

25 Sun A L, Qin Z F, Chen S W, Wang J G. J Mol Catal A, 2004, 210: 189

26 Chen S, Qin Z, Xu X, Wang J G. Appl Catal A, 2006, 302: 185

27 Saito M, Kimura H, Mimura N, Wu J, Murata K. Appl Catal A, 2003, 239: 71

28 Marques S P D, Pinheiro A L, Braga T P, Valentini A, Filho J M, Oliveira A C. J Mol Catal A, 2011, 348: 1 